\title{
Atmospheric Pressure Continuous Production of Solketal from the Acid-Catalyzed Reaction of Glycerol with Acetone
}

\author{
Paula A. Oliveira, ${ }^{a}$ Rodrigo O. M. A. Souza ${ }^{b}$ and Claudio J. A. Mota ${ }^{*, a, c, d}$

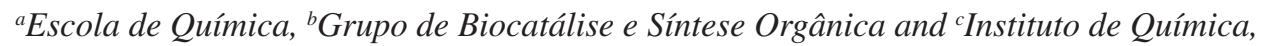 \\ Universidade Federal do Rio de Janeiro, 21949-901 Rio de Janeiro-RJ, Brazil \\ ${ }^{d}$ Instituto Nacional de Ciência e Tecnologia de Energia e Ambiente, Universidade Federal do Rio de \\ Janeiro, 21941-909 Rio de Janeiro-RJ, Brazil
}

\begin{abstract}
A continuous-flow process at atmospheric pressure was designed for the conversion of glycerol to solketal, an oxygenated fuel additive, through the acid-catalyzed reaction of glycerol with acetone. Process optimization was performed by checking the influence of different variables on the conversion and selectivity. The variables examined were: residence time $(12,24,60$ and $120 \mathrm{~min}$ ), catalyst type (Amberlyst-15 and K-10 Montmorillonite), catalyst loading (7, 3, and $1 \mathrm{~g})$, reaction temperature $\left(50,40\right.$ and $\left.30^{\circ} \mathrm{C}\right)$, molar ratio of the reactants $(1: 2,1: 5,1: 10,1: 15$ and $1: 20)$ and solvent used to homogenize the system (dimethylsulfoxide or dimethylformamide). The highest conversion (92\%) was observed with $7.0 \mathrm{~g}$ of Amberlyst-15, reaction temperature of $50{ }^{\circ} \mathrm{C}$, molar ratio of glycerol to acetone of 1:20 and dimethylformamide as solvent. In all cases, solketal isomers (five and six-membered ring ketals) were the only product observed. The results of solketal formation of this study, carried out at atmospheric pressure, were similar to other studies with pressures of up to 120 bar. The utilization of higher catalyst loading and molar ratio of reactants compensate the use of atmospheric pressure to achieve high conversion levels and selectivity to the desired product.
\end{abstract}

Keywords: glycerol, solketal, flow chemistry, acid catalysis

\section{Introduction}

Oil, natural gas and its derivatives are fuels that allow the existence of fast and efficient means of transport, as well as much of the industrial activities in the present days. However, it is very likely that they will not last longer than a few decades, because their reserves are finite, security of supply is problematic in many countries that import them and their use is the main source of $\mathrm{CO}_{2}$, a gas associated with climate changes and global warming. Thus, it is essential to search for substitutes for these fuels, especially from renewable organic matter (biomass). In this context, biodiesel appears as one of the most promising candidates.

Biodiesel is produced through the transesterification of vegetable oils or animal fat with methanol, under base catalysis conditions. ${ }^{1,2}$ In this process, glycerol or glycerin is formed as byproduct in approximately $10 \mathrm{wt} \%$. This biofuel can be used pure or blended with petrodiesel and features a number of environmental benefits. It contains no

*e-mail: cmota@iq.ufrj.br sulfur and aromatic molecules, presents lower emission of carbon monoxide and particulates and its cetane number is high, improving the engine efficiency.

In Brazil, biodiesel is presently blended with the petrodiesel in $7 \mathrm{vol} \%$. A great challenge of the Brazilian biodiesel program is to find economical and environmentally friend uses for the glycerol produced as byproduct. Personal care products, soaps, pharmaceuticals and food are the main sectors that make regular use of glycerol. ${ }^{3}$ However, they cannot absorb alone, all the glycerol produced from the biodiesel industry. Thus, it is necessary to find new applications for this excess of glycerin produced by the biodiesel industry.

The use of glycerin as a raw material to produce other chemicals is gaining interest in recent years. ${ }^{4-7}$ Hydrogenolysis over metal catalysts affords 1,2- and 1,3-propanediols, which can be used in the production of polymers. ${ }^{89}$ Dehydration over acidic catalysts produces acrolein, ${ }^{10-13}$ an important intermediate in the synthesis of acrylic acid and other chemicals. Synthesis gas, a mixture of $\mathrm{CO}$ and $\mathrm{H}_{2}$, can be produced from glycerol aqueous 
phase reforming..$^{14}$ Reaction with dimethyl carbonate can lead to the formation of glycerol carbonate. ${ }^{15}$ Glycerol can also be converted in ethers, acetals/ketal and esters, all of them potential fuel additives. For instance, the reaction of glycerol with isobutene affords tert-butyl-glycerol ethers. ${ }^{16}$ Glycerol ethers can also be produced through the acid-catalyzed reaction of glycerol with alcohols. ${ }^{17,18}$ Glycerol acetals and ketals can be produced through the acid-catalyzed reaction with aldehydes and ketones, respectively. ${ }^{19,20}$ These compounds can be used as fuel additives. ${ }^{21}$ Acetylation of glycerol affords the acetins or glycerol acetates. ${ }^{22}$

We have recently shown ${ }^{23}$ that solketal, the ketal produced in the reaction of glycerol with acetone, improves the octane number and reduces gum formation in gasolines, either with and without ethanol. Therefore, it can be a potential oxygenated gasoline additive, reducing gum formation and improving the octane number. In addition, solketal is easily hydrolyzed in excess water, ${ }^{24}$ indicating that it will not contaminate water sources, as methyl-tert-butyl ether (MTBE) does, and this has been the main reason for this additive to be phased out, because it shows carcinogenic properties. ${ }^{25}$

Continuing our interest on the development of continuous-flow protocols, ${ }^{26}$ we wish to report an atmospheric pressure continuous flow study for the production of solketal, by the acid-catalyzed ketalization of glycerol (Scheme 1).

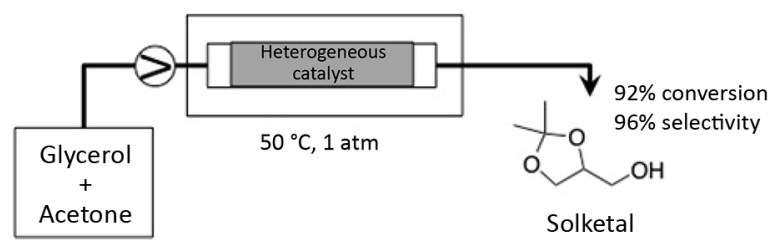

Scheme 1. Continuous-flow production of solketal under atmospheric pressure by acid catalyzed ketalization of glycerol.

\section{Experimental}

\section{General procedure}

Two catalysts were used in the experiments:Amberlyst-15, (particle size $<300 \mu \mathrm{m}$, Sigma-Aldrich, USA) and K-10 Montmorillonite (powder, Fluka, USA). Both were used at the particle size provided by the suppliers. Prior to the catalytic tests, the Amberlyst- 15 was activated at $120^{\circ} \mathrm{C}$ for $2 \mathrm{~h}$ and $\mathrm{K}-10$ Montmorillonite at $150^{\circ} \mathrm{C}$ for $2 \mathrm{~h}$ on an oven and carefully transferred to the flow system. Amberlyst- 15 is reported to have $4.7 \mathrm{mmol}$ of acid sites per $\mathrm{g}$, whereas $\mathrm{K}-10$ has an acidity of $0.007 \mathrm{~mol} \mathrm{~g}^{-1}$, determined by adsorption/desorption of $n$-butylamine. ${ }^{22}$
Solketal formation via glycerol ketalization with acetone was studied in an Asia 110 continuous flow system using a fixed bed of catalyst (Amberlyst-15 or K-10 Montmorillonite). Three packed bed columns, each with its respective volume (including the bed of catalyst), were used. The column used with the highest catalyst loading $(7.0 \mathrm{~g}$ ) has a volume of $12.4 \mathrm{~mL}$, the one used with $3.0 \mathrm{~g}$ of catalyst has a volume of $5.5 \mathrm{~mL}$ and the column used with $1.0 \mathrm{~g}$ of catalyst has $2.4 \mathrm{~mL}$. The operational variables were flow rate, temperature, catalyst loading, type of catalyst (Amberlyst-15 and K-10), molar ratio of reactants and solvent used to homogenize the glycerol/acetone mixture. The solvent was used in the same molar proportion of glycerol in the mixture. The feed containing acetone, glycerol and the solvent (dimethyl sulfoxide, DMSO or dimethylformamide, DMF) at room temperature was pumped continuously at different flow rates into the reactor. Initially, only pure acetone was pumped through the column until the catalytic device reached the desired conditions. The reaction was performed at proper temperature using the heating plate device provided by the Asia system (USA) and atmospheric pressure. Eight samples, at the end of each space time $(0.2 \mathrm{~h})$ processed, were taken and analyzed by capillary gas chromatography coupled with a mass spectrum (Agilent 5975, USA), operating with electron ionization (EI) at $70 \mathrm{eV}$ to obtain the conversion and selectivity. A capillary column $(30 \mathrm{~m} \times 0.25 \mathrm{~mm})$ with a $0.25 \mu \mathrm{m}$ of methyl-phenyl-silicone stationary phase was used to separate the products, with helium as a carrier gas. Aliquots $(0.2 \mathrm{~mL})$ were injected using a heating program from 70 to $200^{\circ} \mathrm{C}$ at $10^{\circ} \mathrm{Cmin}^{-1}$. Table 1 shows the different variables used in this study.

Conversion was calculated using 1,4-dioxane as internal standard with the use of a calibration standard curve. Conversion is defined as the amount of glycerol before and after the reaction, divided by the amount of glycerol before reaction.

The productivity of solketal was calculated taken the molar ratio of glycerol to acetone, without considering the solvent, and calculating the molar concentration of

Table 1. Different parameters used for the continuous flow process of solketal production

\begin{tabular}{lc}
\hline Parameter & Used values \\
\hline Flow rate $/\left(\mathrm{mL} \mathrm{min}^{-1}\right)$ & $0.1 ; 0.2 ; 0.5$ and 1.0 \\
Temperature $/{ }^{\circ} \mathrm{C}$ & $30 ; 40$ and 50 \\
Catalyst loading $/ \mathrm{g}$ & $1.0 ; 3.0$ and 7.0 \\
Type of catalyst & Amberlyst-15; K-10 \\
Glycerol/acetone molar ratio & $1: 2 ; 1: 5 ; 1: 10 ; 1: 15$ and $1: 20$ \\
Solvent & DMSO and DMF \\
\hline
\end{tabular}


glycerol in the mixture by using the density and the molar weight. Then, the conversion was taken to calculate the molar concentration of solketal formed, assuming the stoichiometry of the reaction. The molar concentration of solketal was transformed to mass concentration per hour using the molar weight and the space time of each experiment.

\section{Results and Discussion}

We began our studies evaluating the effect of the flow rate on the conversion. We have used, as a first tentative guess, the following reaction conditions: $50{ }^{\circ} \mathrm{C}, 7.0 \mathrm{~g}$ of Amberlyst-15, glycerol/acetone molar ratio 1:2; DMSO as solvent. The choice of this reaction condition was based on the previous experience of our group in the related reaction (Table 2). It can be seen that no significant change was observed among the flow rates studied, with the glycerol conversion being around $70 \%$, with a selectivity of $100 \%$ to solketal. This result shows that equilibrium is being reached even at the highest flow rate used and the number of acid sites was the same in all experiments.

Table 2. Effect of the flow rate on the conversion and selectivity at $50{ }^{\circ} \mathrm{C}$, $7.0 \mathrm{~g}$ of Amberlyst-15, glycerol/acetone molar ratio 1:2; DMSO as solvent

\begin{tabular}{lccc}
\hline entry & $\begin{array}{c}\text { Flow rate / } \\
\left(\mathrm{mL} \mathrm{min}^{-1}\right)\end{array}$ & $\begin{array}{c}\text { Conversion / } \\
\%^{\mathrm{a}}\end{array}$ & $\begin{array}{c}\text { Selectivity / } \\
\%^{\mathrm{a}}\end{array}$ \\
\hline 1 & 1.0 & 70 & $>99$ \\
2 & 0.5 & 70 & $>99$ \\
3 & 0.2 & 70 & $>99$ \\
4 & 0.1 & 70 & $>99$ \\
\hline
\end{tabular}

${ }^{\mathrm{a} C o n v e r s i o n}$ and selectivity measured by GC analysis.

After this initial assessment, the next step was the evaluation of process stability of the packed bed filled with Amberlyst-15 and K-10 Montmorillonite as an alternative catalyst. Figure 1 shows that glycerol conversion was significantly higher on Amberlyst- 15 than on K-10 Montmorillonite. In addition, this later catalyst showed a slight decrease in conversion with increasing process time, indicative of deactivation. Experiments at batch reaction conditions, using a constant number of acid sites in the medium, also indicated the higher activity of Amberlyst-15, but the difference with respect to K-10 was not so significant. ${ }^{20}$ Nevertheless, in the present study, the loading of catalyst was kept constant $(7.0 \mathrm{~g}$ of each catalyst), instead of the amount of acid sites. Thus, since Amberlyst-15 has more acid sites per $\mathrm{g}$ than K-10, the conversion over this catalyst was significantly higher. It is important to stress that blank reactions, with no catalyst in the reactor system, showed only $2 \%$ of conversion at the base case conditions.

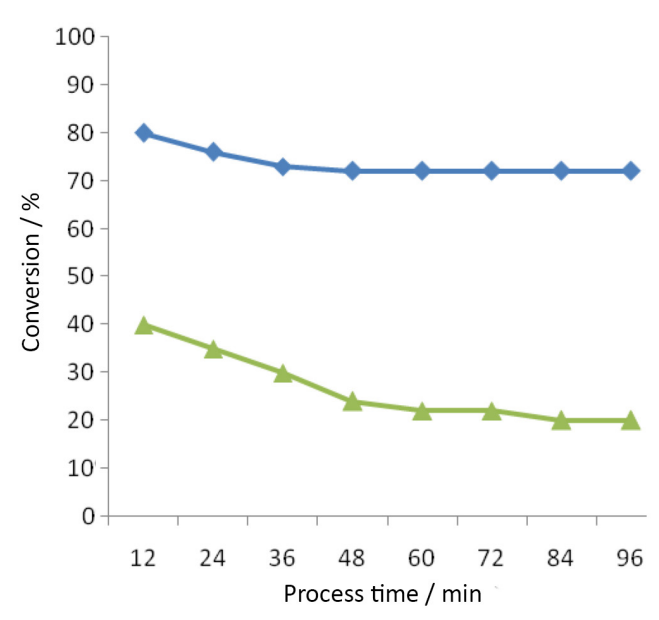

Figure 1. Effect of process time on glycerol conversion $\left(\mathrm{T}=50^{\circ} \mathrm{C}\right.$, flow rate of $1.0 \mathrm{~mL} \mathrm{~min}{ }^{-1}$, glycerol/acetone (1:2), DMSO as solvent); ( $)$ Amberlyst-15; () K-10 Montmorillonite.

Evaluation of catalyst loading was also taken into account but, at this time, we have decided to move forward only with Amberlyst-15 which present better results than K-10 Montmorillonite. Figure 2 shows the effect of catalyst loading (Amberlyst-15) on the conversion. At steady state conditions (after $30 \mathrm{~min}$ ), the highest catalyst loading $(7.0 \mathrm{~g})$ showed the highest conversion. These results may be interpreted in terms of the number of acid sites. As the mass of catalyst in the system increases, the number of active sites on the catalyst does also go up, favoring the reaction rate.

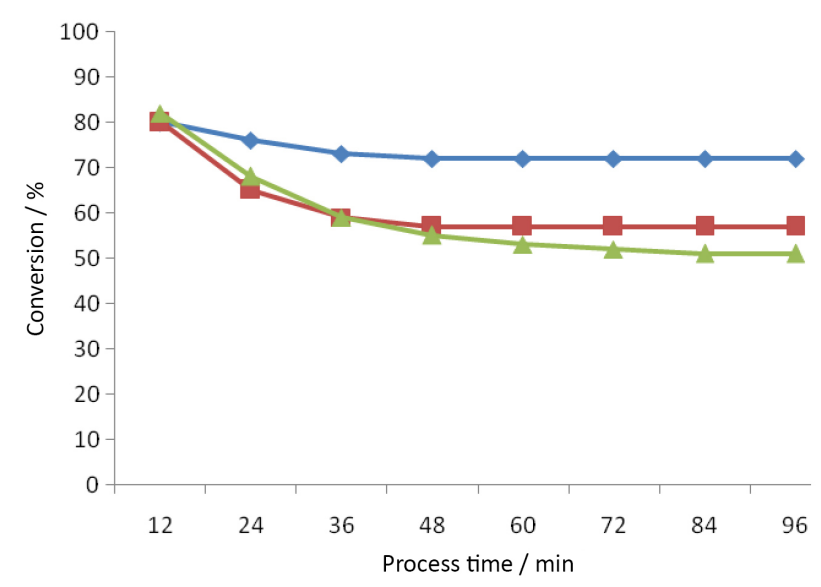

Figure 2. Effect of catalyst (Amberlyst-15) loading on the glycerol conversion $\left(\mathrm{T}=50{ }^{\circ} \mathrm{C}\right.$, flow rate of $1.0 \mathrm{~mL} \mathrm{~min}^{-1}$, glycerol/acetone (1:2), DMSO as solvent); ( ) $7 \mathrm{~g} ;(\square) 3 \mathrm{~g} ;(\Delta) 1 \mathrm{~g}$.

Temperature was also evaluated as an important variable for process optimization and Figure 3 shows the effect of different temperatures on the conversion of glycerol towards 
soketal over Amberlyst-15. As the experiments were carried out at atmospheric pressure, a limit of the temperature, slightly lower of the boiling point of acetone $\left(56^{\circ} \mathrm{C}\right)$, had to be established. At $50{ }^{\circ} \mathrm{C}$ the glycerol conversion was around $72 \%$, but decreased as the temperature goes down.

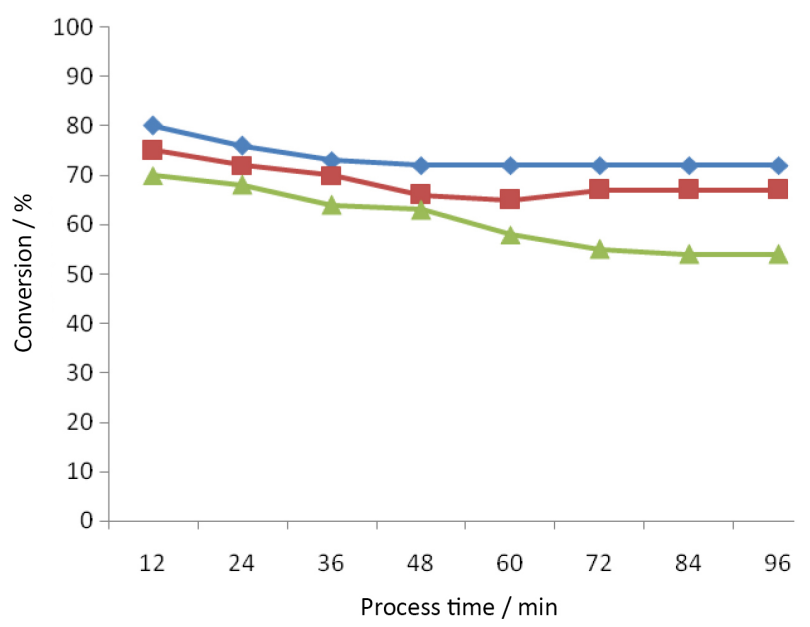

Figure 3. Effect of temperature on the glycerol conversion (flow rate of $1.0 \mathrm{~mL} \mathrm{~min}^{-1}$, glycerol/acetone (1:2), $7.0 \mathrm{~g}$ of Amberlyst-15, DMSO as

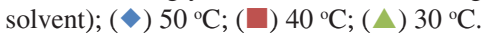

Solvent choice is a very important task during the development of a continuous flow protocol, since all reagents need to be soluble in order to be able for pumping through the packed bed reactor. Figure 4 shows the effect of solvent (DMSO or DMF) on the glycerol conversion. Acetone and glycerol are not completely soluble, requiring the use of a solvent to avoid phase separation. We have previous shown ${ }^{21}$ that DMSO can be used to dissolve glycerol with aliphatic aldehydes. DMSO and DMF are polar aprotic solvent widely used in chemistry. It can be seen on Figure 4 that DMF led to slightly higher conversion (77\%) than DMSO did (72\%).

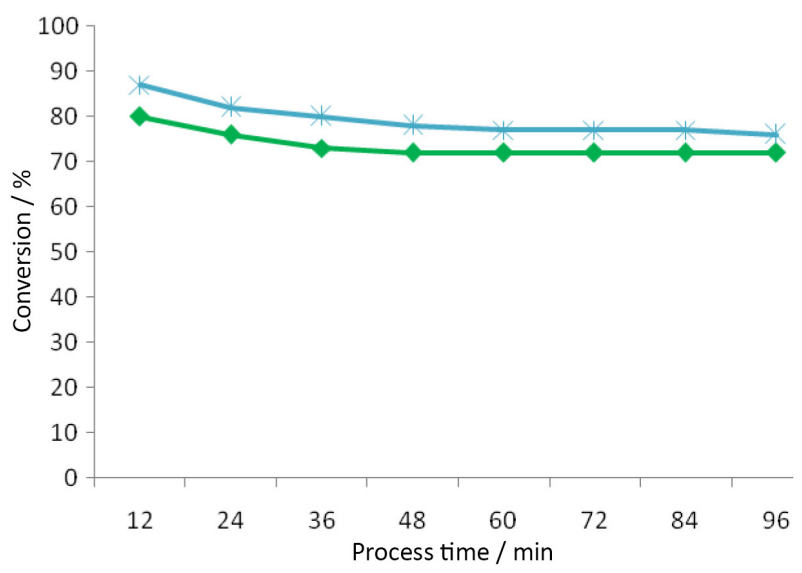

Figure 4. Effect of the solvent on the glycerol conversion $\left(\mathrm{T}=50{ }^{\circ} \mathrm{C}\right.$, $7.0 \mathrm{~g}$ of Amberlyst-15, glycerol/acetone (1:2), flow rate of $\left.1.0 \mathrm{~mL} \mathrm{~min}^{-1}\right)$; $(\diamond)$ DMSO; (*) DMF.
The basicity of the two solvents on aqueous sulfuric acid are similar and slightly higher than acetone. ${ }^{27,28}$ Therefore, equilibrium among protonated DMF, DMSO and acetone must occur, as well as with glycerol. Another possibility would be the different solvation or interaction of DMF and DMSO with the reactants, influencing the reactivity and the energy barrier. DMF has two heteroatoms that may interact through hydrogen bonding with two different molecules. Scheme 2 shows possible pictures of the role of DMF and DMSO in the nucleophilic attack of glycerol to the protonated acetone. A DMF molecule can interact with the protonated acetone and with the secondary hydroxyl group of glycerol. This makes the primary hydoxyl more reactive toward nucleophilic attack of the protonated carbonyl group. On the other hand, with DMSO this situation does not occur. One may infer that DMSO may help the stabilization of the protonated acetone through hydrogen bonding, whereas the glycerol molecule undergoes an intramolecular hydrogen bonding between the secondary and primary hydroxyl groups, which reduce the reactivity toward nucleophilic attack in the carbonyl group, explaining the lower conversion compared with DMF.

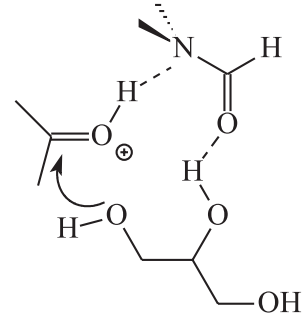

(a)

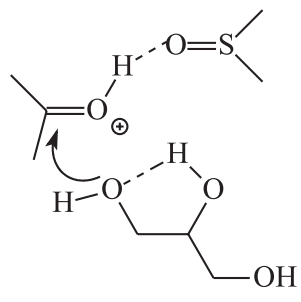

(b)
Scheme 2. Pictorial view of the role of DMF (a) and DMSO (b) in nucleophilic attack of glycerol to protonated acetone.

Ketalization is a reversible reaction and can thus be shifted towards products by increasing the molar ratio of reactants or withdrawing water from the medium. We studied the effect of glycerol to acetone molar ratio on the conversion of the continuous flow ketalization; the results are presented on Figure 5. As expected, the increase in the molar ratio of reactants led to an increase in conversion, which jumped from $72 \%$ at 1:2 glycerol/acetone molar ratio to $87 \%$ at 1:20 glycerol/acetone molar ratio. At higher molar ratios, the two isomers, five and six-membered ring ketals, could be observed with the former being in $96 \%$ selectivity.

Considering that DMF gave slightly better results than DMSO, we decided to run an experiment at the best parameter conditions, which are: $7.0 \mathrm{~g}$ of Amberlyst-15, $1.0 \mathrm{~mL} \mathrm{~min}^{-1}$ of flow rate, at $50{ }^{\circ} \mathrm{C}, 1: 20$ glycerol/acetone molar ratio and DMF, instead of DMSO, as solvent. Under these conditions, the glycerol conversion was $92 \%$, the 


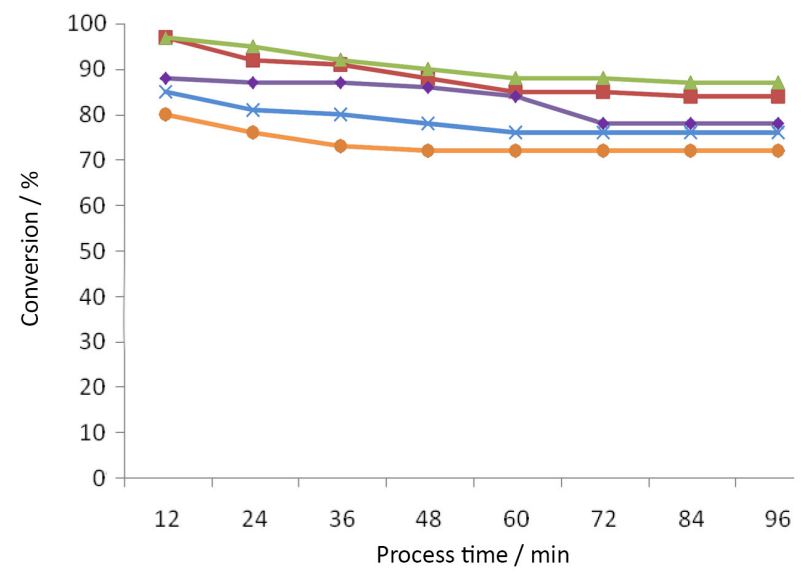

Figure 5. Effect of molar ratio of glycerol to acetone on the glycerol conversion $\left(\mathrm{T}=50^{\circ} \mathrm{C}, 7.0 \mathrm{~g}\right.$ of Amberlyst- 15 , flow rate of $1.0 \mathrm{~mL} \mathrm{~min}{ }^{-1}$; DMSO as solvent); $(\bullet) 1: 2 ;(\times) 1: 5 ;(\bullet) 1: 10 ;(\square) 1: 15 ;(\Delta) 1: 20$.

highest observed in this study at atmospheric pressure, and about 5 points higher than in DMSO.

In recent years, some studies of continuous reactive distillation, ${ }^{29}$ as well as continuous flow production of solketal, from the reaction of glycerol and acetone, using homogeneous ${ }^{30}$ and heterogeneous catalysts ${ }^{31-33}$ appeared in the literature. Most of the heterogeneous catalysts used in the flow production of solketal were sulfonic acid resins, but the studies were carried out at high pressures to increase the solubility of glycerol in acetone. This allows the reaction to proceed more efficiently on the catalyst surface, but usually involves higher costs for pressurizing the system. Table 3 shows a comparison of published works on the continuous solketal formation over sulfonic acid resins at high pressures and the present study, at atmospheric pressure. It can be seen that at our best reaction conditions, the glycerol conversion was similar to the reported in the literature with similar catalysts, but using pressures in the range of 34 to 120 bar. In addition, the productivity, expressed in terms of kg of solketal produced per liter and per hour, was also calculated, taking into account the conversion, space time and molar ratio of acetone to glycerol, as in some articles the volume of solvent used was not clear. The use of higher catalyst loading and molar ratio of reactants, overcome the need for using high pressures. In one experiment, Shirani et al. ${ }^{31}$ reported results at $1 \mathrm{bar}, 60^{\circ} \mathrm{C}$ and $1.5 \mathrm{~g}$ of catalyst loading, achieving $64 \%$ conversion. This value is even lower than our results at $50{ }^{\circ} \mathrm{C}$ and $1: 2$ glycerol/ acetone molar ratio. Therefore, the continuous liquid phase production of solketal can be achieved with over $90 \%$ conversion, by proper choice of catalyst loading and molar ratio of reactants.

In terms of productivity, the space time has a significant effect. Even though we have used a large excess of acetone, our productivity in $\mathrm{kg}$ per liter and hour was higher than the one calculated for the Shirani's work. However, if we consider our lowest glycerol to acetone molar ratio (1:2) and the $77 \%$ conversion observed at this condition (taken form Figure 4), we may calculate a productivity of $2.337 \mathrm{~kg} \mathrm{~L}^{-1} \mathrm{~h}^{-1}$. Thus, if one wants to upscale the process, it might be better to use a lower acetone to glycerol molar ratio, whistle working at reduced space time and higher catalyst loading.

\section{Conclusions}

Solketal was efficiently and continuously produced through the reaction of glycerol with acetone using heterogeneous catalyst. At the best reaction conditions, $1.0 \mathrm{~mL} \mathrm{~min}{ }^{-1}$ of flow rate, $7.0 \mathrm{~g}$ of Amberlyst- 15 as catalyst, $50{ }^{\circ} \mathrm{C}, 1$ bar, 1:20 molar ratio of glycerol to acetone and DMF as solvent, the conversion was $92 \%$, with a selectivity of $96 \%$ to the five-membered ring isomer and $4 \%$ of the six-membered ring ketal. No other product, but the ketal isomers, was observed at the reaction conditions used in this

Table 3. Comparison of studies of continuous flow glycerol formation

\begin{tabular}{|c|c|c|c|c|c|}
\hline Parameter & Shirani $^{\mathrm{a}}$ & Nanda $^{\mathrm{b}}$ & $\mathrm{Nanda}^{\mathrm{c}}$ & Present work & Present work \\
\hline Space time $^{\mathrm{d}} / \mathrm{h}$ & 1 & 0.25 & 0.5 & 0.2 & 0.2 \\
\hline Temperature $/{ }^{\circ} \mathrm{C}$ & 20 & 40 & 25 & 50 & 50 \\
\hline Pressure / bar & 120 & ca. 41 & ca. 34 & ca. 1 & ca. 1 \\
\hline Type of catalyst & Purolite® PD206 & Amberlyst-36 & Amberlyst-36 & Amberlyst-15 & Amberlyst- 15 \\
\hline Catalyst loading / g & 0.77 & - & 2.0 & 7.0 & 7.0 \\
\hline Molar ratio & $1: 5$ & $1: 6$ & $1: 4$ & $1: 20$ & $1: 2$ \\
\hline Solvent & ethanol & ethanol & methanol & DMF & DMF \\
\hline Conversion / \% & 95 & 88 & 94 & 92 & 77 \\
\hline Solketal productivity $/\left(\mathrm{kg} \mathrm{L}^{-1} \mathrm{~h}^{-1}\right)$ & 0.288 & 0.928 & 0.670 & 0.425 & 2.337 \\
\hline
\end{tabular}

${ }^{\mathrm{a}}$ Reference 31 ; ${ }^{\mathrm{b}}$ reference 32 ; ${ }^{\mathrm{c}}$ reference 33 ; ${ }^{\mathrm{d}}$ space time is defined as the time required to process a volume of alimentation, corresponding to the reactor volume; ${ }^{\mathrm{e}}$ calculated taken only the molar ratio of glycerol to acetone, conversion and space time. 
work. This result, using atmospheric pressure, is similar to other studies of solketal formation under flow conditions, but at significantly higher pressures of up to $120 \mathrm{bar}$, which may impact the operational costs. The utilization of higher catalyst loading and molar ratio of reactants compensate the use of atmospheric pressure to achieve high conversion levels and selectivity to the desired product. In addition, the lower space time led to an increased productivity of solketal, compared with other studies. The continuous flow production of solketal may open the possibility of producing this important derivative in high volumes and low costs.

\section{Acknowledgments}

Authors acknowledge financial support from CNPq and FAPERJ.

\section{References}

1. Meher, L. C.; Sagar, D. V.; Naik, S. N.; Renewable Sustainable Energy Rev. 2006, 10, 248.

2. Luque, R.; Lovett, J. C.; Datta, B.; Clancy, J.; Campelo, J. M.; Romero, A. A.; Energy Environ. Sci. 2010, 3, 1706.

3. Mota, C. J. A.; Silva, C. X. A.; Gonçalves, V. L.; Quim. Nova 2009, 32, 639.

4. Zhou, C. H.; Beltramini, J. N.; Fan, Y. X.; Lu, G. Q.; Chem. Soc. Rev. 2008, 27, 527.

5. Pagliaro, M.; Ciriminna, R.; Kimura, H.; Rossi, M.; Pina, C. D.; Angew. Chem., Int. Ed. 2007, 46, 4434.

6. Behr, A.; Eilting, J.; Irawadi, K.; Leschinski, J.; Lindner, F.; Green Chem. 2008, 10, 13.

7. Jérôme, F.; Pouilloux, Y.; Barrault, J.; ChemSusChem 2008, 1, 586.

8. Dasari, M. A.; Kiatsimkul, P. P.; Sutterlin, W. R.; Suppes, G. J.; Appl. Catal., A 2005, 281, 225.

9. Kusunoki, Y.; Miyazawa, T.; Kunimori, K.; Tomishige, K.; Catal. Commun. 2005, 6, 645.

10. Chai, S. H.; Wang, H. P.; Liang, Y.; Xu, B. Q.; J. Catal. 2007, $250,342$.

11. Tsukuda, E.; Sato, S.; Takahashi, R.; Sodesawa, T.; Catal. Commun. 2007, 8, 1349.

12. Pestana, C. F. M.; Guerra, A. C. O.; Ferreira, G. B.; Turci, C. C.; Mota, C. J. A.; J. Braz. Chem. Soc. 2013, 24, 100.
13. Possato, L. G.; Diniz, R. N.; Garetto, T.; Pulcinelli, S. H.; Santilli, C. V.; Martins, L.; J. Catal. 2013, 300, 102.

14. Soares, R. R.; Simonetti, D. A.; Dumesic, J. A.; Angew. Chem., Int. Ed. 2006, 45, 3982.

15. Nogueira, D. O.; Souza, S. P.; Leão, R. A. C.; Miranda, L. S. M.; Souza, R. O. M. A.; RSC Adv. 2015, 5, 20945.

16. Klepacova, K.; Mravec, D.; Bajus, M.; Appl. Catal., A 2005 , 294, 141.

17. Gu, Y.; Azzouzi, A.; Pouilloux, Y.; Jerome, F.; Barrault, J.; Green Chem. 2008, 10, 164;

18. Silva, C. R. B.; Gonçalves, V. L. C.; Lachter, E. R.; Mota, C. J. A.; J. Braz. Chem. Soc. 2009, 20, 201.

19. Deusch, J.; Martin, A.; Lieske, H.; J. Catal. 2007, 245, 428.

20. Silva, C. X. A.; Gonçalves, V. L. C.; Mota, C. J. A.; Green Chem. 2009, 11, 38.

21. Silva, P. H. R.; Gonçalves, V. L. C.; Mota, C. J. A.; Bioresour. Technol. 2010, 101, 6225.

22. Gonçalves, V. L. C.; Pinto, B. P.; Silva, J. C.; Mota, C. J. A.; Catal. Today 2008, 133-135, 673.

23. Mota, C. J. A.; Silva, C. X. A.; Rosenbach Jr., N.; Costa, J.; Silva, F.; Energy Fuels 2010, 24, 2733.

24. Ozório, L. P.; Pianzolli, R.; Mota, M. B. S.; Mota, C. J. A.; J. Braz. Chem. Soc. 2012, 24, 931.

25. Nadim, F.; Zack, P.; Hoag, G. E.; Liu, S. L.; Energy Policy 2001 , $29,1$.

26. Souza, R. O. M. A.; Miranda, L. S. M.; Rev. Virtual Quim. 2014, 6,34 .

27. Bagno, A.; Scorrano, G.; J. Am. Chem. Soc. 1988, 110, 4577.

28. Wada, G.; Bull. Chem. Soc. Jpn. 1969, 42, 890.

29. Clarkson, J. S.; Walker, A. J.; Wood, M. A.; Org. Process Res. Dev. 2001, 5, 630.

30. Monbaliu, J. C. M.; Winter, M.; Chevalier, B.; Schmidt, F.; Jiang, Y.; Hoogendoorn, R.; Kousemaker, M. A.; Stevens, C. V.; Bioresour. Technol. 2011, 102, 9304.

31. Shirani, M.; Ghaziaskar, H. S.; Xu, C. C.; Fuel Process. Technol. 2014, 124, 206.

32. Nanda, M. R.; Yuan, Z.; Qin, W.; Xu, C. C.; Fuel 2014, 128, 113 ;

33. Nanda, M. R.; Yuan, Z.; Qin, W.; Xu, C. C.; Appl. Energy 2014, 123,75 . 